\title{
Üniversite Öğrencilerinin Algıladıkları Değerler, Parasosyal Etkileşim Düzeyleri ile Bilişsel ve Davranışsal İlişki Düzeyleri Arasındaki İlişkinin İncelenmesi
}

DOI: $10.26466 /$ opus. 828113

*

\author{
Esra Teke $e^{*}$ Bülent Dilmaç** - Betül Yavuz *** \\ * Doktora Öğr., Necmettin Erbakan Üniversitesi, AK Eğitim Fakültesi, Konya/Türkiye \\ E-Posta: esradogru1@gmail.com \\ ORCID: 0000-0002-8436-2169 \\ ** Prof. Dr., Necmettin Erbakan Üniversitesi, AK Eğitim Fakültesi, Konya/Türkiye \\ E-Posta: bulentdilmac@gmail.com \\ ORCID: 0000-0001-5753-9355 \\ ***Doktora Öğr., Necmettin Erbakan Üniversitesi, AK Eğitim Fakültesi, Konya/Türkiye \\ E-Posta: betuly.21@hotmail.com \\ ORCID: 0000-0003-0256-8436
}

Öz

$B u$ araştırmanın amacı üniversite öğrencilerinin algıladıkları değerler, parasosyal etkileşim düzeyleri ile bilişsel ve davranışsal ilişki düzeyleri arasındaki ilişkinin incelenmesidir. Araştırmada tarama araştırma yöntemi kullanılmıştır. Araştırma örneklemini 502 üniversite öğrencisi oluşturmuştur. Verilerin toplanmasında Değerler Ölçeğgi, Parasosyal Etkileşim Ölçeği, Bilişsel ve Davranışsal İlişki Ölçeğgi kullanılmıştır. Veriler Google formlar aracılığıyla toplanmıştır. Araştırmada üniversite öğrencilerinin algıladıkları değerler, parasosyal etkileşim düzeyleri ile bilişsel ve davranışsal ilişki düzeyleri arasındaki yordayıcı ilişkiler ve parasosyal etkileşim ile değerler arasındaki ilişkide bilişsel ve davranışsal ilişkinin aracılık rolü "Yapısal Eşitlik Modeli" ile test edilmiştir. Araştırma sonucunda, oluşturulan modelin tüm uyum indeks değerlerinin kabul edilebilir aralıkta olduğu görülmüş ve model kabul edilmiştir. Çalışmada parasosyal etkileşim değişkeninin, değer ile bilişsel ve davranışsal ilişki değişkenini pozitif yönlü yordadı̆̆ bulunmuştur. Bilişsel ve davranışsal ilişki değişkeninin ise değer değgişkenini negatif yönlü yordadı̆̆̆ bulgulanmıştır. Ayrıca parasosyal etkileşim ve değer arasındaki ilişkide bilişsel ve davranışsal ilişkinin aracı değiş̧ken olarak rol oynadığı bulgusuna ulaşılmıştır.

Anahtar Kelimeler: Değer, parasosyal etkileşim, bilişsel ve davranışsal ilişki 
ISSN: 2528-9527

E-ISSN : 2528-9535

Yıl Year: 11

Cilt Volume: 17

Sayı Issue: 35

Mart March 2021

Makalenin Geliș Tarihi Received Date. 19/11/2020 Makalenin Kabul Tarihi Accepted Date. 29/03/2021

\title{
Examination of the Relationship Between University Students' Perceived Values, Parasocial Interaction Levels, and Cognitive and Behavioral Involvement Levels \\ *
}

\begin{abstract}
The aim of this study is to examine the relationship between the values perceived by university students, their parasocial interaction levels and their cognitive and behavioral involvement levels. Survey research method was used in the study. 502 university students has established the study sample. Values Scale, Parasocial Interaction Scale, Cognitive and Behavioral Involvement Scale were used to collect data. The data were collected through Google forms. In the study, the values perceived by university students, the predictive relationships between parasocial interaction levels and cognitive and behavioral involvement levels, and the mediating role of cognitive and behavioral involvements in the relationship between parasocial interaction and values were analyzed according to the "Structural Equation Model". As a result of the research, it was seen that all fit index values of the model created were within the acceptable range and the model was accepted. In the study it was found that the parasocial interaction variable positively predicted the cognitive and behavioral involvement variable and value. It was found that the cognitive and behavioral involvement variable predicted the value variable negatively. In addition, it was found that the cognitive and behavioral involvement played a role as a mediator variable in the relationship between parasocial interaction and value.
\end{abstract}

Keywords: Value, parasocial interaction, cognitive and behavioral involvement 


\section{Giriş}

Televizyon programlarının ve bu programlardaki karakterlerin, insanların televizyona ilgi duymasında önemli bir etken olduğu düşünülmektedir. Bu ilgiyi sağlayan en güçlü ve sağlam programlardan birisi de televizyon dizileridir (Arslan, 2013).

Dizilerdeki olayların birbirine bağlı bir şekilde ilerlemesi, izleyicilerin merak duygusunun uyanmasina ve dizileri takip etme isteklerinin artmasina neden olmaktadır. Ayrıca izleyicilerin sevdikleri karakterleri televizyon ekranlarında görmeleri diziyi takip etmelerini sağlamaktadır. Bu durum izleyiciler ve karakterler arasında bir bağın oluşmasına sebep olmaktadır (Batıün ve Sunal, 2017).

İzleyicilerin dizilerdeki karakterlerden etkilenerek onlarla bir bağ, ilişki kurdukları; fakat dizi karakterlerinin bundan haberdar olmadığı etkileşimi Horton ve Wohl (1956) parasosyal etkileşim olarak ifade etmiştir (Aytulun, 2015). Sood ve Rogers (2000) ise parasosyal etkileşimi bir izleyici üyesinin medya karakteriyle algılanan kişilerarası bir ilişki geliştirmesinin derecesi olarak tanımlamışlardır. Buna göre parasosyal etkileşim tek yönlü bir ilişkidir (Frederick, Lim, Clavio, ve Walsh, 2012; Sözen, 2014).

Alanyazındaki parasosyal etkileşimle ilgili çalışmalar bu etkileşimin sevilen karakterlerle kurulabildiği gibi (Eyal ve Cohen, 2006; Ertuğrul, 2019) sevilmeyen ya da nötr olunan karakterlerle de kurabildiğini (Arda, 2006; Giles, 2002; Hartmann, 2008) göstermektedir.

Rubin ve Perse (1987) çalışmalarında parasosyal etkileşimden bahsederken bilişsel ve davranışsal ilişkiden de bahsedilebileceğini belirtmektedirler. Buna göre izleyicilerin oyuncuların yaşamış olduğu olaylarla ilgili düşünmeleri bilişsel ilişkiyi, izledikleriyle ilgili başkaları ile konuşmaları ise davranışsal ilişkiyi ifade etmektedir. İzleyicilerin dizi bittikten sonra dahi dizideki olanları düşünmeleri, sonraki bölümlerle ilgili tahminlerde bulunmaları, sonraki bölümlerde neler olabileceğine dair diğer insanlarla konuşmaları bilişsel ve davranışsal ilişkiye örnektir.

İzleyici ve dizi karakteri arasında kurulan parasosyal etkileşim, pek çok araştırmacının dikkatini çekmiş ve bu durum araştırmacıların bu alanda çalışmalar yapmasını sağlamıştır (Arda, 2006; Cohen, 2003; Önder, 2019). Alanyazında parasosyal etkileşim ile parasosyal ilişki (Rubin ve Perse, 1987; Sözen, 2014), bağlanma biçimleri (Arslan, 2013; Cohen, 2004), yalnızlık 
(Chory ve Yanen, 2005; Greenwood ve Long, 2009), saldırganlık (Eyal ve Rubin, 2003) futbol fanatizmi (Sözen, 2014) ve evlilik doyumu (Batıün ve Sunal, 2017) gibi değişkenler arasındaki ilişkiye dair çalışmalara rastlanmaktadır. Yapılan araştırmalarda televizyon karşısında geçirilen sürenin (Schmid ve Klimmt, 2011), özdeşliğin (Rumpf, 2012), karakterin çekiciliğinin (Arda, 2006; Hoffner ve Buchanan, 2005; Klimmt, Hartmann, ve Schramm, 2006), TV programında gerçek hayattakilere benzer diyalogların geçmesinin, oyuncuların izleyiciyle konuşuyor gibi gösterilmesinin, medya karakteri ile kurulan yakın ilişkinin (Aytulun, 2015) parasosyal etkileşimin güçlü ve sağlam bir ilişki olarak kurulmasında önemli etkenler olduğu bulunmuştur. Bununla birlikte Moyer-Guse ve Nabi (2010), gözlemlenen karakterlerin davranışlarının model alınmasında motivasyon faktörünün de önemli olduğunu ifade etmişlerdir.

Parasosyal etkileşim, izleyicilere, sosyal davranışları modelleme veya kültürel değerleri öğrenme fursatı da vermektedir (McCourt ve Fitzpatrick, 2001). $\mathrm{Bu}$ açıdan bakıldığında bireylerin kurmuş olduğu parasosyal etkileşimlerin onların değerleri üzerinde de önemli bir etkiye sahip olabileceği söylenebilir.

Değerler, bilişler ve davranışlarımızı etkileyip her davranışın temelinde yer alan, onları yönlendiren olgulardır (Demircioğlu ve Tokdemir, 2008). Bireyin değerliliğini ortaya koyan nitelikler ve donanımlar çerçevesinde tasvir edilen değerler, bireyin kişiliğine, görüşlerine, davranışlarına etki eden etmenlerdir (Yaman, 2014).

Değerler, arzu edilen, davranışlarımız için ölçek görevi görebilecek, bireyin ya da toplumun inandığı vicdani ölçütlere sahip olgulardır. Değerler, sergileyeceğimiz davranışı seçmemizde bizlere rehberlik ederken aynı zamanda başkalarıyla olan iliş̧kilerimize de doğrudan etki eder ( Kapkın, Çalışkan, ve Sağlam, 2018).

Değerler, toplumda teknolojik gelişmelerin yaşanması, eğitim düzeyinin yükselmesi, coğrafi hareketliliklerin artması, kitle iletişim araçlarının yayginlaşması sonucunda değişime uğrayabilmektedir. Bu araçlar bireylere sağladıkları özgürlüğün yanı sıra bireyselleşmeyi, sosyal yabancılaşmayı, empati yoksunluğunu, sorumsuzluk ve sosyal konulara ilgisizliği de beraberinde getirebilmektedir. Aynı zamanda bireylerin gelişmelerden anında haberdar olmalarını ve yurttaşlık bilinçlerinin gelişmesini de sağlayabilmektedirler. Bu açıdan kitle iletişim araçlarının hem olumlu hem de olumsuz etkileri bulunabilmektedir (Sekmen, 2010). Bu bağlamda ilişkiler, değerler, 
tercihler konusundaki algılamalar medya tarafından yönlendirilebilmektedir. Medyada toplumsal değerlerle çatışma örneklerinden biri olarak karşımıza diziler çıkabilmektedir (Ceylan, 2012).

Alanyazında var olan çalışmaların incelenmesi neticesinde televizyonda kültürel farklar ile değerlerin temsillerinin bulunduğu saptanmıştır. Aynı zamanda bu kültürel farklar ve değerlerle ilgili temsillerin, televizyon dizilerinin yanı sıra film, yarışma gibi televizyon programlarında da bulunduğu söylenebilmektedir (Gayretli, 2019). Engelberg ve Sjöberg (2004) yaptıkları çalışmada kişisel yetenekler, kişilik ve duygusal zekâ ile sosyal medya kullanımı arasındaki ilişkiyi araştırmışlardır. Araştırmanın sonucunda sosyal medya kullanımının yalnızlık, kendine özgü değerler, bağlılık ile iş, eğlence arasındaki dengesizlikle ilişkili olduğunu bulmuşlardır. Bunun yanı sıra sosyal medyayı sık kullanan kişilerin yalnızlığa meyilli oldukları, sosyalduygusal becerilerinin gelişmemiş olduğu da gözlenmiştir. Erdoğan (2010), yaptığı çalışmada çocukların televizyondan izledikleri her türlü yayının, onların sosyal ilişkilerinde ve ileriki yaşantılarında edinecekleri değerlerin oluşumunu etkileyebileceğini belirtmektedir. 1940 ve 1950 yılları arasında Daniel Lerner Türkiye'de yapmış olduğu çalışmada kitle iletişim araçlarını seyreden bireylerin geleneksel düşünce ve davranış şekillerinden uzaklaştığını, yeni fikirler geliştirdiğini ve köyden kente göç ettiğini ortaya koyan bulgulara rastlamıştır (Sekmen, 2010)

Yapılan araştırmalar (Erdoğan, 2010; Gayretli, 2019) TV programları, medya ile değerler arasındaki ilişkinin varlığını ortaya koymakta ve bunların bireylerin değerleri, davranışları, tutumları üzerindeki etkisine dikkat çekmektedir. Bu etki, bir radyo sunucusuyla parasosyal etkileşimin dinleyicilerin tutum ve davranışlarını etkilemek için yeterli olabileceğini gösteren bir araştırmayla da ortaya konulmuştur (Rubin ve Step, 2000).

Toplumsal düzeyde ahlaki çöküntülerin giderek çoğalması, teknolojik gelişmelerle birlikte sağlıklı kişilerarası ilişkilerin zayıflaması, aile kurumunun nitelik ve önemini yitirmesi, yolsuzlukların ve yozlaşmanın artması, istismarın her türünün yaygınlaşması, insanoğlunun sebep olduğu çevresel kirlilik ve zararlar gibi birçok olumsuz gelişme değer kavramının daha çok gündeme gelmesine ve değerler eğitimine gereksinimin giderek artmasına sebep olmaktadır (Kenan, 2009). Bu çalışmayla amaçlanan, üniversite öğrencilerinin algıladıkları değerler, parasosyal etkileşim düzeyleri ile bilişsel ve davranışsal ilişki düzeyleri arasındaki ilişkinin incelenmesiyle değerler 
eğitimine duyulan öneme dikkat çekecektir. Ayrıca bu çalışmayla izlenen programların bireyler, üzerindeki etkisi ortaya konarak programların işlevselliği ve sonuçlarına dair farkındalıkların artması sağlanacaktır. Bununla birlikte yapılan araştırmalar incelendiğinde parasosyal etkileşim ve bilişseldavranışsal ilişki ile değerler arasındaki ilişkinin ele alındığı bir çalısmaya rastlanmamıştır. $\mathrm{Bu}$ yönüyle araştırmanın, bahsedilen kavramların daha geniş perspektifte ele alınmasını ve anlaşılmasını sağlayacağı, literatürde konuyla ilgili bilgi boşluğunun doldurulmasında önemli bir işlev göstereceği düşünülmektedir. Bu bağlamda üniversite öğrencilerinin algıladıkları değerler, parasosyal etkileşim düzeyleri ile bilişsel ve davranışsal ilişki düzeyleri arasındaki ilişkinin incelenmesi bu araştırmanın amacını oluşturmaktadır. Bu amaca bağlı olarak alt amaçlar aşağıda görüldüğü şekilde belirlenmiştir;

1. Üniversite öğrencilerinin parasosyal etkileşim düzeyleri, bilişsel ve davranışsal ilişki düzeylerini anlamlı bir şekilde yordamakta mıdır?

2. Üniversite öğrencilerinin parasosyal etkileşim düzeyleri, algıladıkları değerleri anlamlı bir şekilde yordamakta mıdır?

3. Üniversite öğrencilerinin bilişsel ve davranışsal ilişki düzeyleri, algıladıkları değerleri anlamlı bir şekilde yordamakta mıdır?

\section{Yöntem}

\section{Araştırmanın Modeli}

Nicel araştırma modeline sahip olan bu çalışmada, üniversite öğrencilerinin algıladıkları değerler, parasosyal etkileşim düzeyleri ve bilişsel davranışsal ilişki düzeyleri arasındaki ilişkinin incelenmesi amaçlanmıştır. Bu doğrultuda araştırma, tarama modeline göre yapılmıştır. Bu yöntemde, mevcut durumu tespit etmek için araştırma yapılır (Büyüköztürk, Kılıç Çakmak, Akgün, Karadeniz ve Demirel, 2019).

\section{Araştırmanın Çalışma Grubu}

$\mathrm{Bu}$ araştırmanın evrenini, 2019-2020 eğitim öğretim yılında Türkiye'nin çeşitli illerinde üniversitede okuyan öğrenciler oluşturmaktadır. Araştırmanın çalışma grubunu Google formlar aracılığıyla ulaşılan 502 öğrenci oluşturmaktadır. Çalışma grubunun 388'i $(\% 77,2)$ kadın, 114 '̈ü $(\% 22,7)$ ise erkektir. 


\section{Veri Toplama Araçlarn}

Değerler Ölçeği: Ölçek, Dilmaç, Arıcak ve Cesur (2012) tarafından geliştirilmiştir. Değerler ölçeği, 39 değer ifadesi ve 9 alt boyuttan oluşmaktadır. Ölçek likert tiptir ve 0'dan 9'a kadar değer alabilmektedir. Değerler Ölçeği alt boyutlarının Cronbach alfa güvenirlik katsayısı; "Toplumsal Değerler" .90, "Kariyer Değerleri" .80, "Entellektüel Değerler" .78, "Maneviyat" .81, "Materyalistik Değerler" .78, "İnsan Onuru" .61, "Romantik Değerler" .66, “Özgürlük" .65 ve "Fütüvvet" .63 bulunmuştur (Dilmaç, Arıcak ve Cesur, 2012).

Üniversite öğrencilerinin algıladıkları değerler, parasosyal etkileşim düzeyleri ile bilişsel ve davranışsal ilişki düzeyleri arasındaki ilişkinin incelendiği bu araştırmada Cronbach alfa güvenirlik katsayısı; "Toplumsal Değerler" .93, "Kariyer Değerleri" .74, "Entelektüel Değerler" .77, "Maneviyat" .84, "Materyalistik Değerler" .75, "İnsan Onuru" .79, "Romantik Değerler" .74, “Özgürlük" .69, “Fütüvvet” .58 bulunmuştur.

Parasosyal Ölçeği: Parasosyal Etkileşim Ölçeğini, Rubin, Perse ve Powell (1985) geliştirilmiştir. 5'li likert tipi ölçek, 20 maddeden oluşmaktadır (Rubin, Perse ve Powell, 1985). Parasosyal Etkileşim Ölçeğinin Türkçe'ye uyarlama çalışmaları, iki pilot çalışmayla Arda (2006) tarafından gerçekleştirilmiştir. Ölçek, 14 maddeden oluşmaktadır. Uyarlanan ölçeğin üç boyutu (arkadaşlık, empati ve ilgi duyma) bulunmaktadır. Cronbach Alfa iç tutarlık katsayısı .94 olarak bulgulanmıştır (Arda, 2006).

Üniversite öğrencilerinin algıladıkları değerler, parasosyal etkileşim düzeyleri ile bilişsel ve davranışsal ilişki düzeyleri arasındaki ilişkinin incelendiği bu araştırmada Cronbach alfa güvenirlik katsayısı; parasosyal etkileşim ölçeği için .91, ölçeğin alt boyutlarından arkadaşlık için .85, empati için .75 ve ilgi duyma için .85 olarak bulunmuştur.

Bilişsel ve Davranışsal İlişki Ölçeği: Rubin ve Perse (1987) tarafından, bireylerin dizi seyretmedikleri zamanlarda dizilere ilişkin etkinliklerle ilgilenme düzeylerini tespit etmek için geliştirilmiştir. Ölçek, Arda (2006) tarafından Türkçe'ye uyarlanmıştır. 7 maddeden oluşmaktadır. Ölçeğin iki boyutu bulunmaktadır. Bunlar; bilişsel ve davranışsal ilişki boyutlarıdır. Uyarlama çalışmasında, Cronbach Alfa iç tutarlık katsayısı bilişsel ilişki .91 bulunmuştur. Davranışsal ilişki ise .88 olarak bulgulanmıştır (Arda, 2006). 
Üniversite öğrencilerinin algıladıkları değerler, parasosyal etkileşim düzeyleri ile bilişsel ve davranışsal ilişki düzeyleri arasındaki ilişkinin incelendiği bu araştırmada Cronbach alfa güvenirlik katsayısı; bilişsel davranışsal ilişki ölçeği için .90, ölçeğin alt boyutlarından bilişsel ilişki için .86, davranışsal ilişki için ise .89 olarak bulunmuştur.

\section{Verilerin Analizi}

Verilerin analizinde AMOS 24 Programı ve kuramsal modeli test için kullanılan gözlenen ya da gözlenemeyen değişkenler arasındaki nedensel ve karşılıklı bağları meydana çıaran istatiksel tür olan Yapısal Eşitlik Modeli kullanılmışır (Shumacker ve Lomax, 2004).

\section{Bulgular}

Üniversite öğrencilerinin algıladıkları değerler, parasosyal etkileşim düzeyleri ile bilişsel ve davranışsal ilişkilerinin incelenmesi amacıyla yapısal eşitlik modelinden yararlanılmıştır. Bu bağlamda ölçeklerin alt boyutları gözlenen değişkenler olarak, parasosyal etkileşim, değerler, bilişsel ve davranışsal ilişki ise gizil değişkenler olarak kullanılmıştır. Araştırmada yer alan değişkenler arasındaki ilişkilerin belirlenmesi amacıyla yürütülen korelasyon analizi sonuçları Tablo 1'de gösterilmiştir.

Tablo 1. Değerler, parasosyal etkileşim düzeyleri ile bilişsel ve davranışsal ilişkiye dair korelasyon analizi sonuçlan

\begin{tabular}{|c|c|c|c|c|c|c|c|c|c|c|c|c|c|c|}
\hline & 1 & 2 & 3 & 4 & 5 & 6 & 7 & 8 & 9 & 10 & 11 & 12 & 12 & 14 \\
\hline 1 & 1 & $.717^{* *}$ & $.705^{* *}$ & $.543^{* *}$ & $.448^{* *}$ & -.028 & .061 & -.026 & -.074 & .047 & -.063 & .087 & -.021 & .055 \\
\hline 2 & & 1 & $.744^{* *}$ & $.539^{* * *}$ & $.472^{* *}$ & $.095^{*}$ & $.115^{*}$ & .080 & .041 & $.098^{*}$ & .019 & $.173^{* *}$ & .081 & .081 \\
\hline 3 & & & 1 & $.567^{* *}$ & $.494^{* * *}$ & .050 & $.091^{*}$ & .068 & -.015 & .054 & -.008 & $.117^{* *}$ & .021 & $.089^{*}$ \\
\hline 4 & & & & 1 & $.669^{* *}$ & -.021 & .017 & -.068 & -.029 & -.003 & -.028 & $.102^{*}$ & -.048 & .037 \\
\hline 5 & & & & & 1 & -.031 & .036 & .009 & .017 & .016 & -.016 & $.101^{*}$ & .008 & .015 \\
\hline 6 & & & & & & 1 & $.626^{*+}$ & $.720^{* *}$ & $.397^{* *}$ & $.228^{* *}$ & $.429^{* *}$ & $.152^{* *}$ & $.700^{* *}$ & $.592^{* *}$ \\
\hline 7 & & & & & & & 1 & $.690^{* *}$ & $.367^{*}$ & $.531^{* *}$ & $.333^{* *}$ & $.191^{* *}$ & $.625^{* *}$ & $.546^{* *}$ \\
\hline 8 & & & & & & & & 1 & $.407^{\prime \prime}$ & $.339^{* *}$ & $.421^{* *}$ & $.160^{* *}$ & $.684^{* *}$ & $.582^{* *}$ \\
\hline 9 & & & & & & & & & 1 & $.171^{* *}$ & $.614^{* * *}$ & $.158^{* *}$ & $.360^{* *}$ & $.365^{* *}$ \\
\hline 10 & & & & & & & & & & 1 & $.176^{* *}$ & $.235^{* *}$ & $.261^{* *}$ & $.235^{*+}$ \\
\hline 11 & & & & & & & & & & & 1 & $.133^{* *}$ & $.369^{* *+}$ & $.361^{* *}$ \\
\hline 12 & & & & & & & & & & & & 1 & $.176^{*+*}$ & $.160^{* * *}$ \\
\hline 13 & & & & & & & & & & & & & 1 & $.548^{* *}$ \\
\hline 14 & & & & & & & & & & & & & & 1 \\
\hline
\end{tabular}

${ }^{*} \mathrm{p}<.05,{ }^{* *} \mathrm{p}<.01$ 
1: Arkadaşlık, 2: Empati, 3: İlgi Duyma, 4: Bilişsel İlişki, 5: Davranışsal İlişki, 6: Toplumsal, 7: Kariyer, 8: Entellektüel, 9: Maneviyet, 10: Materyalistik, 11: İnsan Onuru, 12: Romatik, 13: Özgürlük, 14: Fütüvvet

Tablo 1'den de görülebileceği gibi parasosyal etkileşim düzeylerinin arkadaşlık, empati, ilgi duyma alt boyutları ile bilişsel ve davranışsal ilişki düzeylerinin bilişsel ilişki ve davranışsal ilişki alt boyutları arasında pozitif yönde anlamlı ilişki bulunmuştur. Aynı şekilde değerlerin alt boyutlarının da birbirleri ile pozitif yönde anlamlı ilişkiler gösterdiği görülmüştür. Bunların yanı sıra empati ile toplumsal $(r=.095$, $p<0.05)$, kariyer $(r=.115, p<0.05)$, materyalistik $(\mathrm{r}=.098, \mathrm{p}<0.05)$ ve romantik değer $(\mathrm{r}=.173, \mathrm{p}<0.01)$ arasında anlamlı ilişki bulunmuştur. İlgi duyma ile kariyer $(\mathrm{r}=.091, \mathrm{p}<0.05)$, romantik $(\mathrm{r}=.117, \mathrm{p}<0.01)$ ve fütüvvet değeri $(\mathrm{r}=.089, \mathrm{p}<0.05)$ arasinda anlamlı bir ilişkinin olduğu görülmüştür. Bilişsel ilişki ile romantik değer $(r=.102$, $\mathrm{p}<0.05$ ) arasında anlamlı bir ilişki bulunmuştur. Davranışsal ilişki ile romantik değer $(r=.101, \mathrm{p}<0.05)$ arasında anlamlı bir ilişki bulunmuştur.

Tablo 2. Test edilen modele ilişkin elde edilen uyum değerleri

\begin{tabular}{lll}
\hline Model Uyum İndeksleri & Modelin Uyum Değerleri & Kabul edilebilir \\
\hline $\mathrm{X}^{2} / \mathrm{sd}$ & 3.064 & $0<\mathrm{X} 2 / \mathrm{sd}<5$ \\
\hline RMSEA & .06 & $0,00 \leq \mathrm{RMSEA} \leq 0,08$ \\
\hline AGFI & .91 & $0,90 \leq \mathrm{AGFI} \leq 1,0$ \\
\hline GFI & .94 & $0,90 \leq \mathrm{GFI} \leq 1,0$ \\
\hline NFI & .94 & $0,90 \leq \mathrm{NFI} \leq 1,0$ \\
\hline TLI & .95 & $0,90 \leq \mathrm{TLI} \leq 1,0$ \\
\hline CFI & .96 & $0,90 \leq \mathrm{CFI} \leq 1,0$ \\
\hline SRMR & .05 & $0,00 \leq \mathrm{SRMR} \leq 0,08$ \\
\hline
\end{tabular}

RMSEA: Yaklaşık Hataların Ortalama Karekökü, AGFI: Düzeltilmiş iyilik uyum indeksi, GFI: İyilik uyum indeksi, NFI: Normlaştırılmış uyum indeksi, TLI: Tucker-Lewis indeksi, CFI: Karşılaştırmalı uyum indeksi, SRMR: Standartlaştırılmış kök artık kareler ortalaması

Tablo 2'de yer alan uyum değerleri incelendiğinde, $\mathrm{X}^{2} / \mathrm{sd}=3.06$, RMSEA=0.06, SRMR=0.05, NFI=0.94, CFI=0.96, GFI=0.94, AGFI=0.91 ve TLI=0.95 olarak bulunmuştur. Modele ilişkin tüm uyum değerlerinin istenen aralıkta olduğu görülmüştür (Byrne, 2010; Kline, 2011; Meydan ve Şeşen, 2015). Bulgular, üniversite öğrencilerinin algıladıkları değerler, parasosyal etkileşim düzeyleri ile bilişsel ve davranışsal ilişki düzeyleri arasındaki ilişkiye dair test edilen modelin kabul edildiğini ortaya koymuştur. 


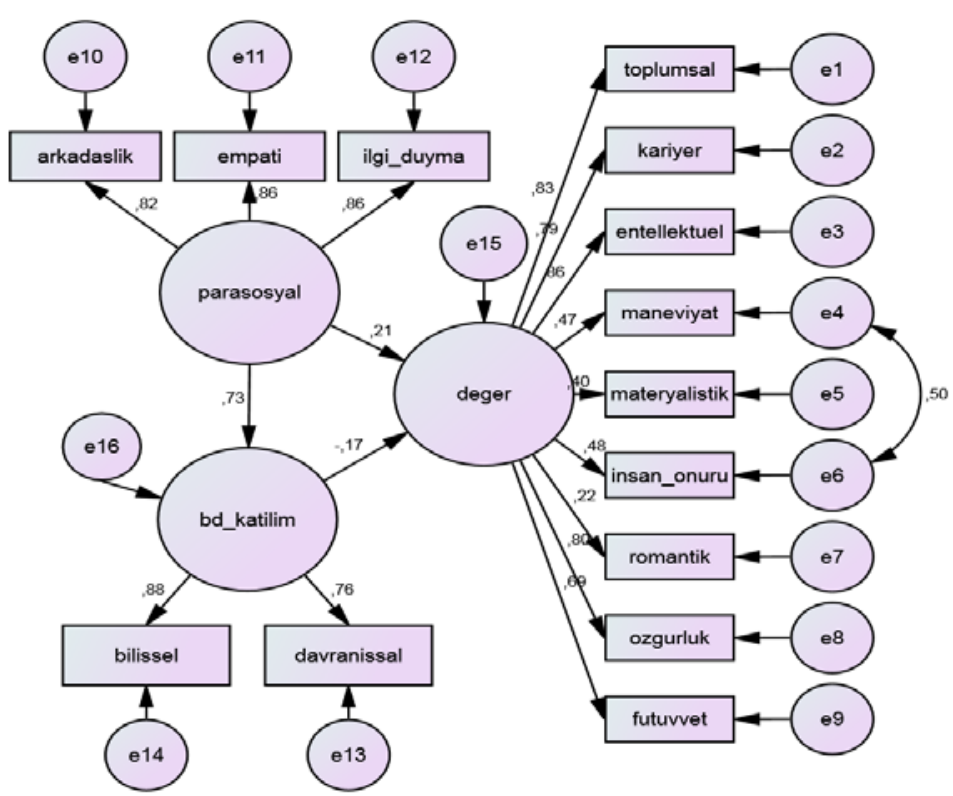

Şekil 1. Değerler, parasosyal etkileşim düzeyleri ile bilişsel ve davranışsal ilişkiye dair yapısal eşitlik modeli

Tablo 3. Parasosyal etkileşim düzeyleri ile algılanan değerler Arasındaki Yordayıcı İlişkilere Yönelik Model

\begin{tabular}{llllccc}
\hline Yordayıcı Değişken & $\begin{array}{l}\text { Bağımlı } \\
\text { Değişken }\end{array}$ & $\begin{array}{l}\text { Toplam } \\
\text { Etki }\end{array}$ & $\begin{array}{l}\text { Doğrudan } \\
\text { Etki }\end{array}$ & $\begin{array}{l}\text { Dolaylı } \\
\text { Etki }\end{array}$ & S. H. & t değeri \\
\hline Parasosyal Etkileşim & $\begin{array}{l}\text { Bilişssel ve } \\
\text { Davranışsal İlişki }\end{array}$ & .73 & .73 & 0 & .04 & $12.63^{* * *}$ \\
\hline Parasosyal Etkileşim & Değer & .08 & .21 & -.13 & .24 & $2.45^{*}$ \\
\hline Bilişsel ve Davranışsal İlişki & Değer & -.17 & -.17 & 0 & .35 & $-2.00^{*}$ \\
\hline
\end{tabular}

${ }^{\text {a }}$ Toplam etki $=$ Doğrudan etki + Dolaylı etki, ${ }^{*} p<0.05,{ }^{* * *} p<0.001$

Şekil 1 ile Tablo 3' ün incelenmesi sonucunda, parasosyal etkileşim değişkeninin bilişsel ve davranışsal ilişkiye etki ettiği ( $t=12.63$, p<.001) gözlenmiştir. Bağlantı katsayısının $\beta=.73$ olduğu görülmüştür. Parasosyal etkileşim ve bilişsel davranışsal ilişki arasında pozitif yönlü, doğrusal yordayıcı ilişkinin yer aldığı gözlenmiştir. Bu durum üniversite öğrencilerinin parasosyal etkileşim düzeyleri arttıkça bilişsel ve davranışsal ilişki düzeylerinin de artacağını göstermiştir.

Modelde parasosyal etkileşim değişkeninin değer değişkenini etkilediği $(\mathrm{t}=2.45, \mathrm{p}<.05)$ gözlenmiştir. Bağlantı katsayısının $\beta=.21$ olduğu görülmüştür. 
Parasosyal etkileşim düzeyleri ile değerler arasında pozitif yönlü doğrusal yordayıcı ilişkinin yer aldığı gözlenmiştir. Bu sonuç, üniversite öğrencilerinin parasosyal etkileşim düzeyleri arttıkça algıladıkları değerlerin de artacağını göstermiştir.

Test edilen modelde bilişsel ve davranışsal ilişkinin değer değişkenini etkilediği ( $t=-2.00, p<.05)$ gözlenmiştir. Bağlantı katsayısının $\beta=.17$ olduğu görülmüştür. Bilişsel ve davranışsal ilişki ile değerleri arasında negatif yönlü yordayıcı ilişkinin olduğu gözlenmiştir. Bulgular, üniversite öğrencilerinin bilişsel ve davranışsal ilişki düzeyleri arttıkça değerlerinin azalacağını göstermiştir.

Yapılan çalışmada, parasosyal etkileşimin bilişsel ve davranışsal ilişki üzerinden değer değişkenine dolaylı etkisinin $\beta=.13$ ( $p<.05)$ olduğu saptanmıştır. Bootstrap analiz sonuçları incelendiğinde parasosyal etkileşim ve değer arasındaki ilişkide bilişsel ve davranışsal ilişkinin kısmi aracı rolü olduğu görülmüştür (\%95 GA [.04, .35]).

\section{Tartışma ve Sonuç}

$\mathrm{Bu}$ araştırmanın amacı üniversite öğrencilerinin algıladıkları değerler, parasosyal etkileşim düzeyleri ile bilişsel ve davranışsal ilişki düzeyleri arasındaki ilişkinin incelenmesidir. Parasosyal etkileşim, televizyon izleyicilerinin medya karakterleriyle kurdukları tek taraflı, kişisel bir ilişkidir (Rubin ve McHugh, 1987). Bu bağlamda izleyicilerin program bitse dahi medya karakterlerinin yaşamış olduğu olaylarla ilgili düşünmeleri bilişsel ilişkiyi, izledikleriyle ilgili başkaları ile konuşmaları ise davranışsal ilişkiyi ifade etmektedir (Rubin ve Perse, 1987). Araştırmadaki bir diğer değişken olan değerler ise, bireylerin ide ve tutumlarını belirlemesinde etkili olan inançlar toplamı olarak tanımlanmaktadır (Dilmaç ve Ulusoy, 2012).

Yapılan bu çalışmada değişkenler arasındaki ilişkinin bir bütün halinde oluşturduğu yapıya dair yapısal eşitlik modeli geliştirilmiş ve test edilmiştir. Test edilen modelin tüm uyum indeks değerlerinin istenen aralıkta olduğu görülmüş (Byrne, 2010; Kline, 2011; Meydan ve Şeşen, 2015) ve model kabul edilmiştir. Ayrıca gerçekleştirilen bu çalışmada, parasosyal etkileşim ve değer arasındaki ilişkide bilişsel ve davranışsal iliş̧inin, aracı değişken rolü oynadığı bulgusuna ulaşılmıştır. 
Modele göre bilişsel ve davranışsal ilişkinin önemli bir yordayıcısının pararsosyal etkileşim olduğu görülmüş̧ür. Üniversite öğrencilerinin sahip olduğu parasosyal etkileşim ile bilişsel ve davranışsal ilişki düzeyleri arasındaki yordayıcı ilişkiler incelenmiştir. İki değişken arasında pozitif yönlü doğrusal bir ilişkinin olduğu bulunmuştur. Bu sonuç bilişsel ve davranışsal ilişki düzeyinin parasosyal etkileşim düzeyine göre değişeceğini ortaya koymaktadır. Rubin ve Perse (1987) yaptıkları çalışmada bilişsel ve davranışsal ilişki ile parasosyal etkileşim arasında pozitif bir ilişki olduğunu bulgulamışlardır. Arslan (2013), TV dizilerinde yer alan karakterler ile kurulan parasosyal etkileşim, bağlanma biçimleri ve yalnızlık üzerine yaptığı çalışmada parasosyal etkileşimin bilişsel ve davranışsal ilişki üzerinde anlamlı bir etkisinin olduğunu bulmuştur. Sözen (2014) futbol fanatizmi, takıma psikolojik bağlılık ve parasosyal etkileşim arasındaki ilişkileri belirlemeye yönelik yaptığı çalışmada futbolcuyla kurulan parasosyal etkileşim ile bilişsel ve davranışsal ilişki arasında pozitif yönde ilişki bulmuştur. Özetle parasosyal etkileşim ile bilişsel ve davranışsal ilişki arasındaki ilişkiye dair yer alan çalışmalar (Greenwood, 2008; Rubin ve McHugh, 1987) bu araştırmadan elde edilen sonuçları destekler niteliktedir.

Yapılan bu araştırmada üniversite öğrencilerinin algıladıkları değerleri etkileyen önemli bir değişkenin öğrencilerin parasosyal etkileşim düzeyleri olduğu görülmüştür. Alanyazında parasosyal etkileşim ile değerler arasındaki ilişkiye dair bir araştırmaya rastlanmamıştır. Fakat parasosyal etkileşime dair yapılan bazı çalışmaların bulguları değerlerin alt boyutlarıyla ilişkilidir. Batıgün ve Sunal'ın (2017) dizilerden algılanan romantik etkinin parasosyal etkileşimi yordayan değişken olduğunu ortaya koyan çalışmalarl, romantik değere örnektir. Benzer bir şekilde medya karakterlerinin ergenlerin cinsiyet rolleri ile cinsel ve romantik konularda şemalar geliştirmelerinde etkili olduğuna yönelik bulgu da (Arnett, 1995) bu değerle ilişkilidir. Özgürlük değeri ile ilişkili olarak Horton ve Wohl (1956) parasosyal etkileşimde bireylerin özgür olduklarını ve diledikleri takdirde geri çekilebildiklerini ortaya koyarlar (Arslan, 2013). Chen (2016), youtube üzerinden parasosyal etkileşim ve dijital benliğin şekillendirilmesi üzerine yaptığı çalışmada YouTube'daki videoların kültürel değerleri içermesi ve ulaşılabilir olmasının parasosyal etkileşim geliştirilmesinde önemli olduğuna dikkat çeker.

Parasosyal etkileşim sonucunda bireyler, sosyal davranışları modelleyebilmekte, kültürel değerleri öğrenebilmektedirler (McCourt ve Fitzpatrick, 
2001). Bu durum parasosyal etkileşimin değerler üzerindeki etkisini gösterebilmektedir. Bireylerin izledikleri karakterlerle özdeşlik kurduğunu, onları model aldığını hatta karakterlerin sahip oldukları değerlerden etkilendiklerini ortaya koyan çalışmalar (Erjem ve Çağlayandereli, 2006; Kırtepe, 2014) buna örnektir. Bu çalışmaları destekler nitelikte Boon ve Lomore (2001), genç yetişkinler arasındaki hayran etkisini açılamaya yönelik gerçekleştirdikleri çalışmada, izleyicilerin beğendikleri ünlüye benzemek için görünümlerinde, tutumlarında ve değerlerinde değişiklik yapabildiklerini ortaya koymuşlardır. Bu sonuçlar parasosyal etkileşim ile değerler arasındaki ilişkiyi destekler niteliktedir.

Modele göre değerin önemli bir yordayıcısının bilişsel ve davranışsal ilişki olduğu görülmektedir. Üniversite öğrencilerinin değerleri ile bilişsel ve davranışsal ilişki düzeyleri arasındaki yordayıcı ilişkiler incelendiğinde iki değişken arasında negatif yönlü bir ilişki bulunmuştur. Bu sonuç değerlerin, bilişsel ve davranışsal ilişki düzeyine göre değişeceğini ortaya koymaktadır. Alanyazında bilişsel ve davranışsal ilişki ile değerler arasındaki ilişkiye dair herhangi bir çalışmaya rastlanmamıştır. Bu bağlamda çalışmanın bulguları, hem bilişsel ve davranışsal ilişki hem de değerlerle ilişkili olan parasosyal etkileşim (Arslan, 2013; Rubin ve Perse; 1987; Sözen, 2014), medya (Rubin ve McHugh, 1987; Batıgün ve Sunal, 2017) gibi değişkenlerle ele alınmıştır.

Konukman (2006) televizyon dizilerinin yaşam tarzı üzerindeki imgelerine yönelik yaptığı çalışmada sevilen dizi karakterlerinin bireylerin günlük yaşantıları üzerinde etkiye sahip olduğunu bulmuştur. Benzer bir şekilde Günaydın (2013) yaptığı sosyolojik incelemede, medya ile toplumsal ve dini değerler arasında bir ilişkinin olduğunu ortaya koymuştur. Güven (2019) ise gerçekleştirdiği çalışmada, bireylerin parasosyal bağ geliştirdiği karakterlerle özdeşim kurabildiğini ve bu karakterlerin bireylerin kültürel değerleriyle çeliştiği takdirde olumsuz etki oluşturabildiğini belirtmiştir. Kasap, Ağzıtemiz, Kızıl ve Yıldırım (2018) parasosyal etkileşim bağlamında televizyon dizilerinin Türk halkı için çok önemli bir yer tuttuğunu ve bazen de bu dizilerin onların hayatlarını fazlasıyla etkileyebildiğini ortaya koymuşlardır. Buna göre izleyiciler izledikleri diziler sonrasında kendilerini istemeden değer, tutum ve fiziksel görünüm açısından değerlendirebilmekte ve bu konuda yeni bir alt tema oluşturabilmektedirler. Alanyazındaki bu araştırmalarla birlikte gerçekleştirilen pek çok çalısma (C1lızoğlu, 2011; Tsai ve 
Men, 2016; Tsiotsou, 2015) bu araştırma sonuçlarıyla paralellik göstermektedir.

Üniversite öğrencilerinin algıladıkları değerler, parasosyal etkileşim düzeyleri ile bilişsel ve davranışsal ilişki düzeyleri arasındaki ilişkinin incelendiği ve nicel olarak yürütülen bu çalışma, nitel araştırmalarla yürütülerek sonuçlar karşılaştıılabilir. Ayrıca çalışma farklı örneklem gruplarıyla ve sonuca etki edebilecek olası değişkenler (cinsiyet, yaş, eğitim durumu vb.) ile tekrarlanarak elde edilen bulgular farklı boyutlarda değerlendirilebilir. Ek olarak araştırmada parasosyal etkileşim düzeylerinin, bilişsel ve davranışsal ilişki düzeylerinin üniversite öğrencilerinin değerlerini yordadığı görülmüştür. Bu sonuç, üniversite öğrencilerinin algıladıkları değerlerin dizi karakterleri ile kurdukları parasosyal etkileşim ile bilişsel ve davranısal ilişkiden etkilendiğini ortaya koymuştur. Bu bağlamda üniversite öğrencilerinin de izleyici hedef kitlesi içerinde yer alan dizilerin senaryoları oluşturulurken değerler göz önünde bulundurulabilir ve dizi karakterleri değerlerin kazandırılmasında model olabilirler. 
EXTENDED ABSTRACT

\title{
Examination of the Relationship Between University Students' Perceived Values, Parasocial Interaction Levels, and Cognitive and Behavioral Involvement Levels
}

\author{
$*$ \\ Esra Teke - Bülent Dilmaç - Betül Yavuz \\ Necmettin Erbakan Üniveritesi
}

Television programs and the characters in these programs are thought to be an important factor in people's interest in television. One of the most powerful programs that provide this interest is the television series (Arslan, 2013). The fact that the events in the series progress in a connected way causes the audience's curiosity to awaken and their desire to follow the series increases. In addition, seeing the characters they love on television screens enables the viewers to follow the series. This situation creates a bond between the audience and the characters (Batigün and Sunal, 2017).

The viewers are influenced by the characters in the TV series and establish a bond and relationship which characters of the TV series are not aware; Horton and Wohl (1956) expressed this interaction as parasocial interaction (Aytulun, 2015). Sood and Rogers (2000) defined parasocial interaction as the degree to which an audience member develops a perceived interpersonal relationship with the media character.

Rubin and Perse (1987) stated in their study that while talking about parasocial interaction, cognitive and behavioral relationships can also be mentioned. To them, the viewers' thinking about the events the actors have experienced indicates the cognitive relationship, and their talking with others about what they watch indicates the behavioral relationship. The audience's thinking about what happened in the show even after the show is over, making predictions about the next episodes, talking with other people about what might happen in the next episodes are examples of cognitive and behavioral relationships. 
The parasocial interaction established between the audience and the character of the TV series has attracted the attention of many researchers, and this has enabled researchers to work in this field (Arda, 2006; Cohen, 2003; Önder, 2019). In the literature, parasocial interaction and parasocial relationship (Rubin and Perse, 1987; Sözen, 2014), attachment styles (Arslan, 2013; Cohen, 2004), loneliness (Chory and Yanen, 2005; Greenwood and Long, 2009), aggression (Eyal and Rubin , 2003), there are studies on the relationship between variables such as football fanaticism (Sözen, 2014) and marital satisfaction (Batıgün and Sunal, 2017). In the researches, the time spent in front of the television (Schmid and Klimmt, 2011), identity (Rumpf, 2012), the attractiveness of the character (Arda, 2006; Hoffner and Buchanan, 2005; Klimmt, Hartmann, and Schramm, 2006), It has been found that the transition of the actors as if they are talking to the audience, the close relationship established with the media character (Aytulun, 2015) are important factors in establishing parasocial interaction as a strong and solid relationship. However, Moyer-Guse and Nabi (2010) stated that the motivation factor is also important in modeling the behaviors of the observed characters.

Parasocial interaction also provides the audience with the opportunity to model social behaviors or learn cultural values (McCourt and Fitzpatrick, 2001). From this point of view, it can be said that the parasocial interactions that individuals have established can have an important effect on their values.

Values are phenomena that affect our cognitions and behaviors and are at the basis of every behavior and guide them (Demircioğlu \& Tokdemir, 2008). The values described within the framework of the qualities and qualifications that reveal the worthiness of the individual are the factors that affect the individual's personality, views and behaviors (Yaman, 2014).

Studies (Erdoğan, 2010; Gayretli, 2019) reveal the existence of the relationship between the media and values and draw attention to the effects of these on the values, behaviors and attitudes of individuals. This effect has also been demonstrated by research showing that parasocial interaction with a radio host can be sufficient to affect the attitudes and behaviors of listeners (Rubin and Step, 2000).

Many negative developments such as increasing moral degradation in society, weakening of healthy interpersonal relationships with technological 
developments, losing the quality and importance of the family institution, increasing corruption and corruption, widespread use of all kinds of abuse, environmental pollution and harms caused by humankind have come to the fore more and more. It causes an increasing need for values education (Kenan, 2009).The aim of this study is to draw attention to the importance of values education by examining the relationship between the values perceived by university students, their parasocial interaction levels and their cognitive and behavioral relationship levels. In addition, this study will reveal the effects of the programs watched on individuals and increase awareness of the functionality and results of the programs. When the conducted studies were examined, there was no study on the relationship between parasocial interaction and cognitive-behavioral relationship and values. In this respect, it is thought that the research will enable the mentioned concepts to be handled and understood in a wider perspective and will play an important role in filling the information gap on the subject in the literature. In this context, the purpose of this study was to examine the relationship between the values perceived by university students, their parasocial interaction levels, and their cognitive and behavioral relationship levels.

Survey research method was used in the study. 502 university students has established the study sample. Values Scale, Parasocial Interaction Scale, Cognitive and Behavioral Involvement Scale were used to collect data. The data were collected through Google forms. In the study, the values perceived by university students, the predictive relationships between parasocial interaction levels and cognitive and behavioral involvement levels, and the mediating role of cognitive and behavioral involvements in the relationship between parasocial interaction and values were analyzed according to the "Structural Equation Model".

As a result of the research, it was seen that all fit index values of the model created were within the acceptable range (Byrne, 2010; Kline, 2011; Meydan and Şeşen, 2015) and the model was accepted. In the study it was found that the parasocial interaction variable positively predicted the cognitive and behavioral involvement variable and value. It was found that the cognitive and behavioral involvement variable predicted the value variable negatively. In addition, it was found that the cognitive and behavioral involvement played a role as a mediator variable in the relationship between parasocial interaction and value. 
Some suggestions were made as a result of this quantitative study examining the relationship between university students' perceived values, parasocial interaction levels and cognitive and behavioral relationship levels. Accordingly, the research can be carried out with qualitative research and the results can be compared. In addition, the findings obtained by repeating the study with different sample groups and possible variables that may affect the result (gender, age, educational status, etc.) can be evaluated in different dimensions. Additionally, in the study, it was seen that parasocial interaction levels, cognitive and behavioral relationship levels predicted the values of university students. This result revealed that the values perceived by university students were affected by the parasocial interaction they establish with the characters of the TV series, and the cognitive and behavioral relationship. In this context, values can be taken into consideration while creating the scenarios of the TV series that university students are within the target audience and the characters of the series can be a model for gaining values.

\section{Kaynakça / References}

Arda, S. (2006). Predictors of parasocial interaction with the favorite and the least desirable characters portrayed in Tv serials. Yayımlanmamış Yüksek Lisans Tezi. Orta Doğu Teknik Üniversitesi Sosyal Bilimler Enstitüsü, Ankara.

Arnett, J. J. (1995). Adolescents' uses of media for self-socialization. Journal of youth and adolescence, 24(5), 519-533.

Arslan, Ö. (2013). TV dizilerinde yer alan karakterler ile kurulan parasosyal etkileşim: bağlanma biçimleri ve yalnızlık açısından bir inceleme. Yayınlanmamaış Yüksek Lisans Tezi. Ankara Üniversitesi Sosyal Bilimler Enstitüsü, Ankara.

Aytulun, G. (2015). Ergenlerde parasosyal etkileşim: Internette gerçek benlik, kendilik algısı ve sosyal kaygı arasındaki ilişkiler. Yayımlanmamış Yüksek Lisans Tezi, Ankara Üniversitesi Sosyal Bilimler Enstitüsü, Ankara.

Batıgün, D. A. ve Sunal, B. A. (2017). TV dizilerinde yer alan karakterlerle kurulan parasosyal etkileşim: Evlilik doyumu, psikolojik belirtiler ve bazı sosyodemografik değişkenler açısından değerlendirme. Türk Psikoloji Dergisi, 32(79), 52-62.

Boon, S. D. ve Lomore, C. D. (2001). Admirer-celebrity relationships among young adults: Explaining perceptions of celebrity influence on identity. Human communication research, 27(3), 432-465. 
Büyüköztürk, Ş., Kılıç Çakmak, E., Akgün, Ö. E., Karadeniz, Ş. ve Demirel, F. (2019). Eğitimde bilimsel araştırma yöntemleri. Ankara: Pegem Akademi.

Byrne, B. M. (2010). Structural equation modeling with AMOS: Basic concepts, applications, and programming. New York: Taylor and Francis.

Ceylan, Y. (2012). Toplumsal değerler ve medya etiği. Dicle Üniversitesi Sosyal Bilimler Enstitüsü Dergisi, 4(7), 45-58.

Chen, C. P. (2016). Forming digital self and parasocial relationships on YouTube. Journal of Consumer Culture, 16(1), 232-254.

Chory-Assad, R.M. ve Yanen, A. (2005). Hopelessness and loneliness as predictors of older adults' involvement with favorite television performers. Journal of Broadcasting \& Electronic Media, 49(2), 182- 201.

Cılızoğlu, G. (2011). Kitle iletişim araçlarında yer alan kurgusal sosyal mesajlar: Televizyon dizilerinde kitleselleştirilen değerlere yönelik bir analiz. Selçuk Üniversitesi İletişim Fakültesi Akademik Dergisi, 6(4), 90-100.

Cohen, J. (2003). Parasocial break-ups: Measuring individual differences in responses to the dissolution of parasocial relationships. Mass Communication $\mathcal{E}$ Society, 6(2), 191-202.

Cohen, J. (2004). Parasocial break-up from favorite television characters: The role of attachment styles and relationship intensity. Journal of Social and Personal Relationships, 21(2), 187-202.

Demircioğlu, İ. ve Tokdemir, M. (2008). Değerlerin oluşturulma sürecinde tarih eğitimi: Amaç, işlev ve içerik. Değerler Ĕ̆itimi Dergisi 15(6), 69-88.

Dilmaç, B. ve Ulusoy, K. (2012). Değerler eğitimi. Ankara: Pegem Akademi.

Dilmaç, B., Arıcak, O. T. ve Cesur, S. (2014). A validity and reliability study on the development of the values scale in Turkey. Educational Sciences: Theory $\mathcal{E}$ Practice, 14(5), 1661-1671.

Engelberg, E. ve Sjöberg, L. (2004). Internet use, social skills, and adjustment. Cyberpsychology and behavior, 7(1), 41-47.

Erdoğan, S. (2010). Erken çocukluk döneminde televizyonun sosyal gelişime ve değerler eğitimine etkisi. International Conference on New Trends in Education and Their Implications içinde (s. 764-767).

Erjem, Y. ve Çağlayandereli, M. (2006). Televizyon ve gençlik: Yerli dizilerin gençlerin model alma davranişi üzerindeki etkisi. CÜ Sosyal Bilimler Dergisi, 30(1), 15-30.

Ertuğrul, S. (2019). Ürün yerleştirmenin satın alma niyeti üzerindeki etkisinde parasosyal etkileşimin rolü. Yayımlanmamış Yüksek Lisans Tezi, Eskişehir Osmangazi Üniversitesi Sosyal Bilimler Enstitüsü, Eskişehir. 
Eyal, K. ve Cohen, J. (2006). When good friends say goodbye: A parasocial breakup study. Journal of Broadcasting \& Electronic Media, 50(3), 502-523.

Eyal, K. ve Rubin, A.M. (2003). Viewer agression and homophily, identification, and parasocial relationships with television characters. Journal of Broadcasting \& Electronic Media, 47(1), 77-98.

Frederick, E. L., Lim, C. H., Clavio, G. ve Walsh, P. (2012). Why we follow: An examination of parasocial interaction and fan motivations for following athlete archetypes on Twittter. International Journal of Sport Communcation, $5,481-502$.

Gayretli, H. E. (2019). Televizyon dizilerinde kültürel farkların değerler bağlamında temsili. Yayımlanmamış Yüksek Lisans Tezi, İstanbul Arel Üniversitesi Sosyal Bilimler Enstitüsü, İstanbul.

Giles, D. C. (2002). Parasocial interaction: A review of the literature and a model for future research. Media Psychology, 4(3), 279-305.

Greenwood, D. N. (2008). Television as escape from self: Psychological predictors of media involvement. Personality and Individual Differences, 44(2), 414-424.

Greenwood, D.N. ve Long, C.R. (2009). Psychological predictors of media involvement: Solitude experiences and the need to belong. Communication Research, 36(5), 637-654.

Günaydın, F. (2013). Toplumsal ve dini değerlerin görsel medyada sunumu üzerine sosyolojik bir inceleme-Ekmek Teknesi dizisi örneği. Yayımlanmamış Yüksek Lisans Tezi, Ankara Üniversitesi Sosyal Bilimler Enstitüsü, Ankara.

Hartmann, T. (2008). Parasocial interactions and paracommunication with new media characters. E. A. Konijn, S. Utz, M. Tanis ve S. B. Barnes (Ed.), Mediated Interpersonal Communication. New York, NY: Routledge.

Hoffner, C. ve Buchanan, M. (2005). Young adults' wishful identification with television characters: The role of perceived similarity and character attributes. Media psychology, 7(4), 325-351.

Kapkın, B., Çalışkan, Z. ve Sağlam, M. (2018). Türkiye'de 1999-2017 yılları arasında değerler eğitimi alanında yapılmış lisansütü çalışmaların incelenmesi. Değerler Ĕ̆itimi Dergisi, 35(16), 185-209.

Kasap, E. Z., Ağzıtemiz, F., Kızıl, N., ve Yıldırım, A. (2018). Understanding the nature of the relationship established with turkish tv serial characters/türk tv dizilerindeki karakterlerle kurulan ilişkinin doğasını anlamak. RES-Research Studies Anatolia Journal, 1(2), 237.

Kenan, S. (2009). Modern eğitimde kaybolan nokta: Değerler eğitimi. Kuram ve Uygulamada Ĕ̈itim Bilimleri, 9(1), 259-295. 
Kurtepe, S. (2014). Televizyon dizilerinin toplum üzerindeki etkileri sosyo-kültürel bir çözümleme-Erzurum örneği. Yayımlanmamış Doktora Tezi. Atatürk Üniversitesi Sosyal Bilimler Enstitüsü, Erzurum.

Klimmt, C., Hartmann, T., ve Schramm, H. (2006). Parasocial interactions and relationships. J. Bryant \& P. Borderer (Ed.), Psychology of entertainment içinde (s. 291-313). New York: Routledge.

Kline, R. B. (2011). Principles and practice of structural equation modeling. New York: The GuilfordPress.

Konukman, E. A. (2006). Medya ve kültür: Son dönem televizyon dizilerinin yaşam tarzı üzerindeki imgeleri. Yayımlanmamış Yüksek Lisans Tezi, Gazi Üniversitesi Sosyal Bilimler Enstitüsü, Ankara.

McCourt, A. ve Fitzpatrick, J. (2001). The role of personal characteristics and romantic characteristics in parasocial relationships: A pilot study. Journal of Mundane Behavior, 2(1), 42-58.

Meydan, C. M. ve Şeşen, H. (2015). Yapısal eşitlik modellemesi Amos uygulamaları. Ankara: Detay Yayıncilik.

Moyer-Guse, E. ve Nabi, R. L. (2010). Explaining the effects of narrative in an entertainment television program: Overcoming resistance to persuasion. Human Communication Research, 36(1), 26-52.

Önder, Ş. (2019). Yetişkin bağlanma boyutlan ile parasosyal etkileşimin parasosyal ayrllk ve ayrllk anksiyetesi ile ilişkisi. Yayımlanmamış Yüksek Lisans Tezi. Üsküdar Üniversitesi Sosyal Bilimler Enstitüsü, İstanbul.

Rubin, A. M. ve Perse, E. M. (1987). Audience activity and soap opera involvement: A Uses and effects investigation. Human Communication Research, 14(2), 246-268.

Rubin, A. M. ve Step, M. M. (2000). Impact of motivation, attraction, and parasocial interaction of talk radio listening. Journal of Broadcasting and Electronic Media, 44(4),635-654.

Rubin, A. M., Perse, E. M. ve Powell, R. A. (1985). Loneliness, parasocial interaction and local television news viewing. Human Communication Research, 12(2), 155-180.

Rubin, R. R. ve McHugh, M. P. (1987) Development of parasocial interaction relationships. Journal of Broadcasting \& Elektronic Media, 31(3), 279-292.

Rumpf, R.E. (2012). The predictors of parasocial interaction and their effects on perceived persuasivenes. San Diego State University, California. 
Schmid, H. ve Klimmt, C. (2011). A magically nice guy: Parasocial relationships with Harry Potter across different cultures. The International Communication Gazette, 73(3), 252-269.

Sekmen, M. (2010). Küreselleşme ve değerler bağlamında televizyon yarışma programlarmın bir analizi: Biri Bizi Gözetliyor, Var Misin Yok Musun, Pop Star yarışmalarıyla sinırlandırılmış olarak. Yayımlanmamış Yüksek Lisans Tezi. Atatürk Üniversitesi Sosyal Bilimler Enstitüsü, Erzurum.

Shumacker, R. ve Lomax, R. G. (2004). A beginner's guide to structural equation modeling. NY: Taylor \& Francis Group.

Sood, S. ve Rogers, E. M. (2000). Dimensions of parasocial interaction by letterwriters to a popular entertainment-education soap opera in India. Journal of Broadcasting \& Electronic Media, 44(3), 386-414.

Sözen, A. I. (2014). Parasosyal etkileşim, terör yönetimi kuramı ve futbol fanatizmi. Yayımlanmamış Yüksek Lisans Tezi. Ankara Üniversitesi Sosyal Bilimler Enstitüsü, Ankara.

Tsai, W. H. S. ve Men, L. R. (2017). Social CEOs: The effects of CEOs' communication styles and parasocial interaction on social networking sites. New media \& society, 19(11), 1848-1867.

Tsiotsou, R. H. (2015). The role of social and parasocial relationships on social networking sites loyalty. Computers in Human Behavior, 48, 401-414.

Yaman, E. (2014). Değerler eğitimi. Ankara: Akçağ Yayınları.

\section{Kaynakça Bilgisi / Citation Information}

Teke, E., Dilmaç, B. ve Yavuz, B. (2021). Üniversite öğrencilerinin alg1ladıkları değerler, parasosyal etkileşim düzeyleri ile bilişsel vedavranışsal ilişki düzeyleri arasındaki ilişkinin incelenmesi. OPUS-Uluslararası Toplum Araştırmaları Dergisi, 17(35), 2918-2939. DOI: 10.26466/opus.828113 